\title{
KLF10 Gene Expression Modulates Fibrosis in Dystrophic Skeletal Muscle
}

\author{
Joseph X. DiMario
}

From the Department of Cell Biology and Anatomy, Rosalind Franklin University of Medicine and Science, Chicago Medical School, North Chicago, Illinois

\begin{abstract}
Dystrophic skeletal muscle is characterized by fibrotic accumulation of extracellular matrix components that compromise muscle structure, function, and capacity for regeneration. Tissue fibrosis is often initiated and sustained through transforming growth factor- $\beta$ (TGF- $\beta$ ) signaling, and Krüppel-like factor 10 (KLF10) is an immediate early gene that is transcriptionally activated in response to TGF- $\beta$ signaling. It encodes a transcriptional regulator that mediates the effects of TGF- $\beta$ signaling in a variety of cell types. This report presents results of investigation of the effects of losS of KLF1O gene expression in wild-type and dystrophic (mdx) skeletal muscle. On the basis of RT-PCR, Western blot, and histological analyses of mouse tibialis anterior and diaphragm muscles, collagen type I (Col1a1) and fibronectin gene expression and protein deposition were increased in $\mathrm{KLF}_{1} \mathrm{O}^{-/-}$mice, contributing to increased fibrosis. $\mathrm{KLF} \mathrm{O}^{-/-}$mice displayed increased expression of genes encoding SMAD2, SMAD3, and SMAD7, particularly in diaphragm muscle. SMAD4 gene expression was unchanged. Expression of the extracellular matrix remodeling genes, MMP2 and TIMP1, was also increased in KLF10-deficient mouse muscle. Histological analyses and assays of hydroxyproline content indicated that the loss of KLF1O increased fibrosis. Dystrophic KLF10-null mice also had reduced grip strength. The effects of loss of KLF10 gene expression were most pronounced in dystrophic diaphragm muscle, suggesting that KLF10 moderates the fibrotic effects of TGF- $\beta$ signaling in chronically damaged regenerating muscle. (Am J Pathol 2018, 188: 1263-1275; https://doi.org/10.1016/j.ajpath.2018.01.014)
\end{abstract}

The murine X-linked muscular dystrophy (mdx) mouse is an animal model of human Duchenne muscular dystrophy. Both disease states are characterized by complete absence of the dystrophin protein, a component of the dystrophinglycoprotein complex that mediates cytoskeleton connectivity to the muscle fiber extracellular matrix (ECM). Loss of dystrophin destabilizes muscle cell integrity during contraction, leading to muscle fiber necrosis. ${ }^{1}$ Appendicular musculature in mdx mice exhibits varying amounts of muscle fiber degeneration and regeneration, depending on muscle fiber type and age. Fast twitch muscle fibers, such as those that comprise the tibialis anterior (TA) muscle, are preferentially, but not exclusively, affected. ${ }^{2}$ Extensive muscle degeneration begins at approximately 4 weeks of age, with compensatory regeneration peaking at approximately 6 weeks. By week 10 , degeneration has subsided to low persistent levels, and regeneration of the acute degeneration event is complete. ${ }^{3}$ Interestingly, unlike appendicular musculature, the mdx diaphragm muscle is characterized by chronic progressive degeneration with accompanying functional reductions in strength and twitch speed. ${ }^{4}$ The histopathology of the mdx diaphragm is, therefore, more closely analogous to the progressive muscle wasting in Duchenne muscular dystrophy patients.

Dystrophic skeletal muscle is also characterized by progressive fibrosis, an excessive accumulation of ECM components. In skeletal muscle, fibrosis primarily involves expansion of the endomysium and perimysium. Both collagen type I and fibronectin are principle components of the ECM in fibrotic muscle tissue. ${ }^{5,6}$ Within fibrotic skeletal muscle, muscle fiber size is often reduced, contributing to loss of muscle cell volume and mass. However, the nature of the mechanistic relationship between increased ECM accumulation and reduced muscle fiber size is not well understood and may well be dependent on the underlying cause of fibrosis

Supported by Rosalind Franklin University of Medicine and Science Disclosures: None declared. 
and persistence of the causative factors (eg, chronic degenerative disease versus repeated trauma). Regardless of the causative factors, muscle fibrosis is typically associated with compromised muscle function, including reduced strength and increased dynamic stiffness. The contribution of individual components of fibrotic ECM, such as collagen and fibronectin, to compromised muscle function remains unclear and is not always readily correlated with all measures of altered function. ${ }^{7}$ The regenerative capacity of fibrotic skeletal muscle is also compromised. ${ }^{8}$ Although mdx muscle fibers have increased numbers of satellite cells and increased proliferative response to mitogenic factors, such as fibroblast growth factor $2,{ }^{9}$ net muscle regeneration in the $\mathrm{mdx}$ diaphragm and Duchenne muscular dystrophy muscle is outpaced by muscle fiber necrosis and fibrosis. Ultimately, fibrosis is a major impediment to skeletal muscle recovery of normal structure and function in the dystrophic state. ${ }^{6,10,11}$

Transforming growth factor- $\beta$ (TGF- $\beta$ ) is central to regulation of the regenerative response to skeletal muscle injury and disease as well as the cellular and molecular mechanisms that lead to fibrosis. TGF- $\beta$ signaling, through membraneassociated TGF- $\beta$ type I and type II receptors, stimulates fibroblasts to increase production of collagen and fibronectin. ${ }^{12,13}$ TGF- $\beta$ activity also regulates expression of ECM remodeling proteins, such as matrix metalloproteinases (MMPs), tissue inhibitors of MMPs (TIMPs), and plasminogen activator inhibitor type 1 (PAI-1). ${ }^{14}$ In addition, TGF- $\beta$ activity controls the regenerative capacity of muscle satellite cells. TGF- $\beta$ represses myogenic cell differentiation by interference with myogenin-mediated gene expression. ${ }^{15,16}$ Levels of TGF- $\beta$ are increased in mdx mouse diaphragm and gastrocnemius muscles. ${ }^{12,17}$ The role of TGF- $\beta$ in the $\mathrm{mdx}$ phenotype is demonstrated by studies that reduce TGF- $\beta$ activity. Expression of a dominant negative TGF- $\beta$ receptor (TGF- $\beta$ R) and administration of a TGF- $\beta$ neutralizing antibody both reduced mdx muscle fibrosis. ${ }^{18,19}$ Conversely, muscle-specific TGF- $\beta 1$ overexpression in transgenic mice yielded increased fibrosis and muscular atrophy. ${ }^{20}$

Expression of TGF- $\beta$-inducible early gene 1 [alias Krüppellike factor $10(K L F 10)]$ is induced soon after cell exposure to TGF- $\beta$. KLF10 gene expression is induced as early as 30 minutes after TGF- $\beta$ treatment and reaches a maximum within 2 hours of induction. KLF10 protein levels reach a maximum shortly thereafter ( 2 to 3 hours). ${ }^{21} K L F 10$ is expressed in human fetal osteoblasts, mesangial cells, fibroblasts, $\mathrm{T}$ cells, hippocampal neurons, $\mathrm{PC} 12$ cells, and mouse cardiomyocytes. ${ }^{22-28}$ $\mathrm{KLF} 10$ is a $\mathrm{C}_{2} \mathrm{H}_{2}$ zinc finger transcription factor that functions as a transcriptional regulator of TGF- $\beta$ responsive genes. The KLF family of transcriptional regulators contains members that can function as transcriptional activators or repressors by binding to GC-rich cis elements in transcriptional regulatory regions. Although KLF10 mediates TGF- $\beta$ signaling via positive transcriptional regulation, it also can function as a transcriptional repressor. For example, in avian skeletal muscle cells, KLF10 interacts with a GC element in the upstream regulatory region of the fibroblast growth factor receptor 1
(FGFRl) gene, repressing its expression. This effect on FGFRI gene expression generally correlates with the altered proliferation and differentiation of $\mathrm{C}_{2} \mathrm{C}_{12}$ cells overexpressing $K L F 10 .{ }^{29,30}$ KLF10 also mediates TGF- $\beta$ signaling through transcriptional regulation of genes encoding SMAD isoforms. KLF10 represses SMAD7 gene expression, but conversely activates SMAD2 gene expression. ${ }^{31,32}$ This altered SMAD signaling, particularly SMAD2/3 signaling, has subsequently been linked to muscle fibrosis and loss of muscle regenerative capacity, characteristic of the dystrophic phenotype. ${ }^{33,34}$

KLF10-deficient mice display a variety of defects. They display an osteopenic phenotype with significantly weakened femurs, reduced cortical bone thickness, and reduced vertebral bone volume. ${ }^{35}$ This is likely because of a decrease in the total number of osteoblasts and corresponding reduction in the rate of bone formation, especially in female mice. ${ }^{36}$ Fast and slow twitch muscle fibers from KLF10-deficient mice have altered mechanical properties. ${ }^{37}$ They also display connective tissue defects in tendon ultrastructure after injury, with delayed expression of TGF- $\beta$ and delayed healing. ${ }^{38} \mathrm{X}$-ray microdiffraction experiments revealed that tail tendon fibers of $K L F 10^{-/-}$mice are disorganized, with a total decrease in the amount of collagen in the tendons. ${ }^{39}$ Interestingly, $K L F 10^{-1-}$ mice display cardiac defects, including hypertrophic cardiomyopathy with increased fibrosis, indicating a possible role for KLF10 in modulating fibrosis. ${ }^{40}$ Therefore, the loss of KLF10 affects production and deposition of ECM components, apparently with tissue-specific outcomes.

This study analyzed the effects of KLF10 gene deletion on expression of genes in the TGF- $\beta$ signaling pathway with a focus on those genes related to fibrosis in skeletal muscle tissue. The study also analyzed the histopathology of TA and diaphragm muscles from KLF10-deficient mice compared with wild-type mice and from KLF10-deficient mdx mice compared with mdx mice. The functional effect of KLF10 loss was assessed by grip strength measurements.

\section{Materials and Methods}

\section{Animals}

$K L F 10^{-1-}$ mice were generated, as previously described ${ }^{41}$ and obtained from Dr. Thomas C. Spelsberg (Mayo Clinic, Rochester, MN). Briefly, exons 1 and 2 as well as $2.3 \mathrm{~kb}$ of $5^{\prime}$ flanking region were replaced with the neomycin resistance gene in a targeting vector, which was then injected into C57BL/ 6 blastocysts. $K L F 10^{-/-}$mice in a congenic background were obtained after breeding against the C57BL/6 wild-type mouse background for at least eight generations. ${ }^{36} \mathrm{KLF} 10^{-1-}$ mice were bred against the mdx mouse genetic background (C57BL) for eight generations to yield $K L F 10^{-1-} / \mathrm{mdx}$ mice.

\section{Real-Time Quantitative RT-PCR}

RNA was obtained from 1-year-old mouse diaphragm and TA muscles using RNA-Stat 60 reagent, according to the 
manufacturer's instructions (Tel-Test Inc, Friendswood, TX). cDNA synthesis from RNA samples was primed with oligo-dT and random hexamers. Amplification was performed in triplicate using real-time quantitative RT-PCR SYBR Green master mix, including ROX passive reference dye (Applied Biosystems, Foster City, CA). GAPDH mRNA amplification was used as a reference for normalization of amplification variability across samples. Expression levels of each gene were calculated by determination of $\Delta \Delta \mathrm{C}_{\mathrm{T}}$. The oligonucleotides used for amplification are listed in Table 1.

\section{Western Blot Analysis}

Protein from 1-year-old mouse diaphragm and TA muscles was extracted by glass grinder homogenization in ice-cold protein extraction buffer, $\mathrm{pH} 7.4(50 \mathrm{mmol} / \mathrm{L}$ Tris, 150 $\mathrm{mmol} / \mathrm{L} \mathrm{NaCl}, 1 \%$ Triton $\mathrm{X}-100,1 \%$ sodium deoxycholate, $0.1 \% \mathrm{SDS}, 1 \mathrm{mmol} / \mathrm{L}$ EDTA, $10 \mathrm{mmol} / \mathrm{L} \mathrm{NaF}, 10 \mathrm{mmol} / \mathrm{L}$ sodium orthovanadate, and $20 \mathrm{mmol} / \mathrm{L}$ sodium pyrophosphate). Homogenized extracts were set on ice for 10 minutes and then centrifuged for 10 minutes at $16,000 \times g$ in an Eppendorf centrifuge at $4^{\circ} \mathrm{C}$. Supernatants were collected and stored at $-80^{\circ} \mathrm{C}$. Protein samples were denatured by addition of $2 \times$ Laemmli's buffer, followed by incubation at $95^{\circ} \mathrm{C}$ for 5 minutes. Samples were electrophoresed in $7.5 \%$ polyacrylamide gels and transferred to nitrocellulose membrane. Blots were incubated in blocking solution [5\% nonfat dry milk, $0.05 \%$ Tween-20 in phosphate-buffered saline (PBS)] overnight at $4^{\circ} \mathrm{C}$. Blots were then incubated in primary antibody, diluted in blocking solution, for 1 hour at room temperature. The following antibodies were used at the indicated dilutions: KLF10 at 1:100 (AB85970; Abcam, Cambridge, UK), fibronectin at 1:100 (C-20; Santa Cruz Biotechnology, Dallas, TX), embryonic myosin heavy chain (EMyHC) at 1:10 (CRL2039; ATCC, Manassas, VA),

Table 1 Primers Used for RT-PCR

\begin{tabular}{|c|c|}
\hline Gene & Oligonucleotides \\
\hline GAPDH & $\begin{array}{l}\text { F: } 5^{\prime} \text {-GACCCCTTCATTGACCTCAACTAC-3' } \\
\text { R: 5'-CACGGAGGCCATGCCAGYGAG- } 3^{\prime}\end{array}$ \\
\hline KLF10 & $\begin{array}{l}\text { F: } 5^{\prime}-C T G A C T G C A T C A G C G C C A T C T A C T G G C C-3^{\prime} \\
\text { R: 5'-CATCTGGCAGATGACAGGCAGGGGTGGC-3' }\end{array}$ \\
\hline Col1a1 & $\begin{array}{l}\text { F: } 5^{\prime}-\text { GAAGAACTGGACTGTCCCAACC-3' } \\
\text { R: } 5^{\prime}-\text { ACCTTGAACTCCAGTAGCACCG-3' }\end{array}$ \\
\hline Fibronectin & $\begin{array}{l}\text { F: } 5^{\prime} \text {-GACGCATCACCTGTACCTCCAG-3' } \\
\text { R: } 5^{\prime}-\text { CATCAACGATGCACTGGTCTCG-3' }\end{array}$ \\
\hline MMP2 & $\begin{array}{l}\text { F: } 5^{\prime} \text {-CGCGTAAAGTATGGGAACGCTG-3' } \\
\text { R: 5'-GTAGTTGGTTGTGGTCGCACAC-3' }\end{array}$ \\
\hline TIMP1 & $\begin{array}{l}\text { F: } 5^{\prime}-\text { AATGCCGCAGATATCCGGTACG-3' } \\
\text { R: } 5^{\prime}-\text { TGGCAGGCAAGCAAAGTGACGG-3' }\end{array}$ \\
\hline SERPINE1 & $\begin{array}{l}\text { F: 5'-CGGATGCCATCTTTGTCCAGCG-3' } \\
\text { R: } 5^{\prime}-\text { AGATGTTGGTGAGGGCGGAGAG-3' }\end{array}$ \\
\hline SMADT & $\begin{array}{l}\text { F: } 5^{\prime} \text {-CCAACTGCAGGCTGTCCAGATG-3' } \\
\text { R: } 5^{\prime} \text {-CACAAAGCTGATCTGCACGGTG-3' }\end{array}$ \\
\hline
\end{tabular}

$F$, forward; R, reverse.
SMAD2 at 1:200 (511300; Life Technologies, Carlsbad, CA), SMAD3 at 1:200 (511500; Life Technologies), SMAD4 at 1:200 (AB40759; Abcam), SMAD7 at 1:200 (216428; Abcam), TGF- $\beta$ R at 1:200 (AB31013; Abcam), and $\alpha$-actin at 1:5000 (A2172; Sigma, St. Louis, MO). Blots were washed five times with PBS plus $0.05 \%$ Tween-20 and then incubated in secondary antibody (Santa Cruz Biotechnology) diluted 1:2000 in blocking solution for 1 hour at room temperature. Blots were washed as before. Protein bands were visualized using the ECL Chemiluminescence Detection Kit (GE Healthcare, Little Chalfont, UK), according to the manufacturer's instructions. Protein band intensities were quantitated using ImageJ software version 1.46 (NIH, Bethesda, MD; http://imagej. nih.gov/ij) and normalized against corresponding actin protein band intensities.

\section{Histological Analysis}

Diaphragm and TA muscles from 1-year-old mice were frozen in OCT Compound (Sakura Finetek, Torrance, CA) and cryosectioned (10 $\mu \mathrm{m}$ thick). Sections were obtained throughout the midportion of each muscle with at least $100-\mu \mathrm{m}$ separation between sections. Six sections were obtained for each muscle. Some sections were stained for collagen using Masson trichrome stain, according to the manufacturer's instructions (Sigma). Other serial sections were immunostained at room temperature, as follows. Sections were fixed in $4 \%$ formaldehyde in PBS for 10 minutes and then washed in PBS twice for 5 minutes each. For immunostaining with the phosphorylated (phospho)-SMAD2/3 antibody, sections were then immersed in ice-cold methanol for 10 minutes, followed by a wash in PBS for 5 minutes at room temperature. Sections were then incubated in blocking solution (5\% horse serum, $2 \%$ bovine serum albumin in PBS) for 1 hour. Most primary antibodies, diluted in blocking solution, were applied for 1 hour at room temperature. The phospho-SMAD2/3 antibody was applied overnight at $4^{\circ} \mathrm{C}$. The following antibodies were diluted as indicated: antilaminin at 1:500 (AB11575; Abcam), anti-fibronectin at 1:100 (SC8422; Santa Cruz Biotechnology), anti-EMyHC at 1:5, and phospho-SMAD2/3 at 1:200 (8828; Cell Signaling Technology, Danvers, MA). Sections were washed in PBS, and the following secondary antibodies, diluted in blocking solution as indicated, were applied to the serial sections for 1 hour: fluorescein isothiocyanate-conjugated anti-rabbit $\operatorname{IgG}(1: 100)$ to detect anti-laminin antibody, Texas red-conjugated antimouse $\operatorname{IgG}(1: 100)$ to detect anti-fibronectin and antiEMyHC antibodies, and Texas red-conjugated anti-rabbit IgG to detect the phospho-SMAD2/3 antibody. Sections were stained with DAPI for 10 minutes and then washed with PBS, as before. Images of sections were collected using a Nikon Eclipse 80i epifluorescence microscope (Nikon, Tokyo, Japan). For determination of muscle fiber cross-sectional areas, microscopic fields at $\times 20$ magnification were randomly selected, and the area within each muscle fiber basement membrane, as shown by laminin immunostaining, was outlined 
and quantified by Nikon Elements software version 3.22. All muscle fibers within a field were measured. Six fields per muscle section were analyzed. For determination of the percentage of muscle tissue composed of muscle fibers, microscopic fields were randomly selected, and individual muscle areas were summed to obtain the collective area of all muscle fibers within the microscopic field. The area of the field of view was quantified by Nikon Elements software. The sum of the muscle fiber areas was then divided by the total tissue area within the field of view. Six microscopic fields per muscle section were analyzed. Six sections of each muscle, isolated from six different mice, were analyzed.

\section{Hydroxyproline Assay}

Hydroxyproline content was measured by an assay based on previously developed assays. ${ }^{42,43}$ Muscle tissue was carefully trimmed of connective tissue, and wet weights were measured. The tissue was then hydrolyzed in $2 \mathrm{~N} \mathrm{NaOH}$ in Eppendorf tubes placed in boiling water for 30 minutes. After cooling to room temperature, 10 to $50 \mu \mathrm{L}$ aliquots of the sample in a total volume of $50 \mu \mathrm{L}$ of $2 \mathrm{~N} \mathrm{NaOH}$ were added to $450 \mu \mathrm{L}$ of chloramine $\mathrm{T}$ solution $[1.46 \mathrm{~g}$ chloramine $\mathrm{T}$ trihydrate (01,779; Thermo Fisher Scientific, Waltham, MA) in $5.2 \mathrm{~mL} \mathrm{H}_{2} \mathrm{O}$, followed by addition of $13 \mathrm{~mL}$ of buffer solution $(250 \mathrm{mmol} / \mathrm{L}$ citric acid, $1.2 \%$ acetic acid, $880 \mathrm{mmol} /$ $\mathrm{L}$ sodium citrate, and $850 \mathrm{mmol} / \mathrm{L} \mathrm{NaOH}, \mathrm{pH} 6.0$ ), and then $7.8 \mathrm{~mL}$ of 2-methoxyethanol with gentle warming to fully dissolve the chloramine T]. The mixture was incubated at room temperature for 25 minutes. Ehrlich's Reagent $5 \mathrm{~g} \mathrm{p}$ dimethylaminobenzaldehyde (D-71; Fisher) in $22.2 \mathrm{~mL}$ of absolute ethanol and $11.1 \mathrm{~mL}$ concentrated sulfuric acid] was freshly prepared for each assay, and $500 \mu \mathrm{L}$ of the reagent was added to the reaction, which was then mixed and incubated at $65^{\circ} \mathrm{C}$ for 20 minutes. Absorbance of the solution at $560 \mathrm{~nm}$ was determined using a Genesys $10 \mathrm{~S}$ spectrophotometer (Thermo Fisher Scientific). Hydroxyproline content was calculated using a standard curve of 0 to $20 \mu \mathrm{g}$ purified hydroxyproline (H54409; Sigma) and normalized against the total volume of the hydrolyzed sample and the muscle tissue wet weight.

\section{Grip Strength}

Mouse forelimb grip strength was measured using a grip strength meter equipped with a pull bar (Columbus Instruments, Columbus, $\mathrm{OH}$ ) and set at peak tension mode. Five male and five female mice of each genotype were assessed. Each mouse was tested five times with a 3-minute rest period between each repetition.

\section{Statistical Analysis}

Data were analyzed using one-way analysis of variance. For real-time quantitative RT-PCR and Western blot analyses, gene expression data from the tibialis anterior of $K L F 10^{-1-}$, $\mathrm{mdx}$, and $K L F 10^{-/-} / \mathrm{mdx}$ mice were compared with data from the tibialis anterior of wild-type mice. Similarly, gene expression data from the diaphragm of the experimental genotypes were compared with data from the wild-type diaphragm control. Tibialis anterior and diaphragm gene expression from $\mathrm{KLF} \mathrm{O}^{-/-} / \mathrm{mdx}$ mice were also compared with gene expression from the respective wild-type control muscles. Data from experiments that quantified phosphoSMAD, collagen content, muscle fiber area, percentage area muscle fiber, and grip strength were similarly analyzed using analysis of variance. Before analysis of variance analyses, data groups were verified to have equal variance, with a confidence of $95 \%(\alpha=0.05)$ using a two-tailed F-test. For pairwise comparisons, Welch's $t$-test was applied, followed by Bonferroni correction method using SPSS software version 24 (IBM, Armonk, NY). Statistical significance was established with $P<0.05$, unless otherwise indicated.

\section{Results}

\section{Gene Expression Analysis}

Initial characterization of the effects of KLF10 gene deficiency in skeletal muscle focused on genes indicative of fibrosis [eg, collagen type 1 (Collal) and fibronectin] and genes associated with remodeling of extracellular matrix [eg, MMP2, TIMP1, and PAII (official name SERPINE1)]. Characterization was performed by analyses of gene expression using real-time quantitative RT-PCR (Figure 1). RNAs were isolated from 1-year-old diaphragm and TA muscles from wild-type, $K L F 10^{-/-}$, $\mathrm{mdx}$, and $K L F 10^{-1-} / \mathrm{mdx}$ mice. Analysis was performed using mice at 1 year of age to allow for induction of fibrosis over time under normal conditions of activity. With regard to KLF10 gene expression, modest levels of RNA were detected in wild-type diaphragm and TA muscles, as revealed by gel electrophoresis of amplified cDNA product. Both diaphragm and TA muscles from $\mathrm{mdx}$ mice had significantly higher levels of KLF10 gene expression. KLF1O gene expression in $\mathrm{mdx}$ diaphragm and TA muscles was increased approximately 2.3 - and 0.5 -fold, respectively, compared with wild-type muscle. As expected, $K L F 10$ gene expression was not detected in $K_{L F 10^{-1-}}$ or $K L F 10^{-1-} / \mathrm{mdx}$ diaphragm or TA muscles.

Analyses of Collal and fibronectin gene expression revealed increased levels in $K L F 10^{-1-}$ mice. Collal gene expression was consistently increased in diaphragm muscle compared with TA muscle in all four mouse genotypes tested. Within diaphragm muscles, no significant differences in Collal gene expression were detected in $\mathrm{KLFIO}^{-1-}$ or mdx diaphragm and TA muscles compared with wild-type muscles. However, both diaphragm and TA muscles from $K L F 10^{-1-} / \mathrm{mdx}$ mice had increased levels of Collal gene expression relative to wild-type, $K L F 10^{-1-}$, and $\mathrm{mdx}$ mouse muscles. Unlike Collal, fibronectin gene expression in wild-type and $\mathrm{KLF}^{-\mathrm{O}^{-/}}$diaphragm muscle was not 


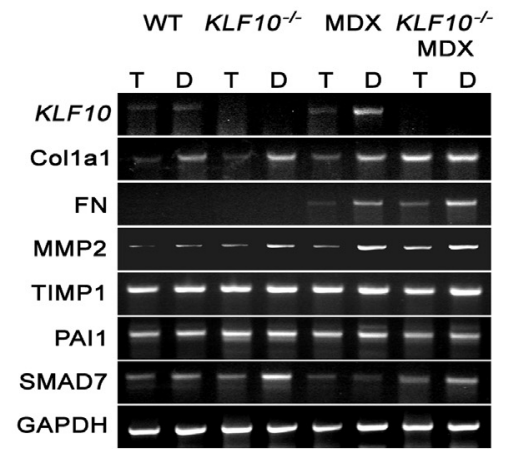

Col1a1

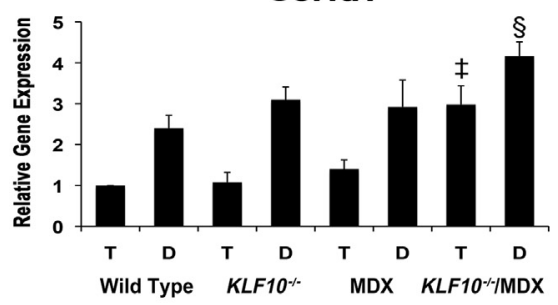

MMP2

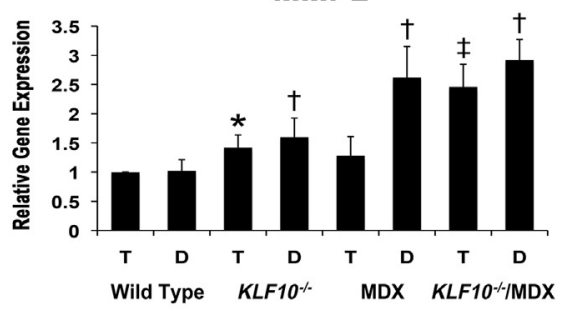

PAI1

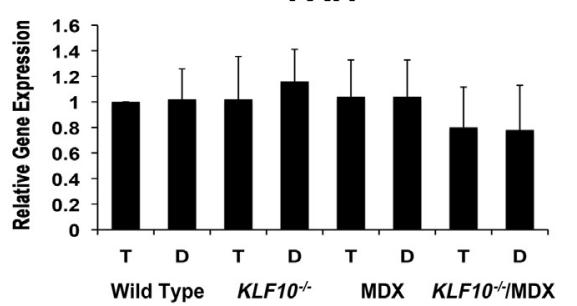

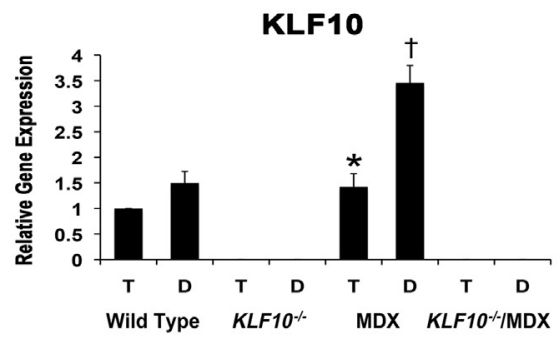

Fibronectin

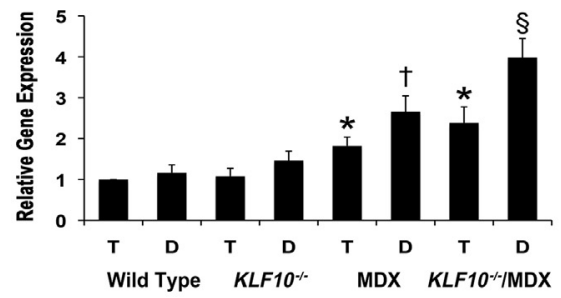

TIMP1

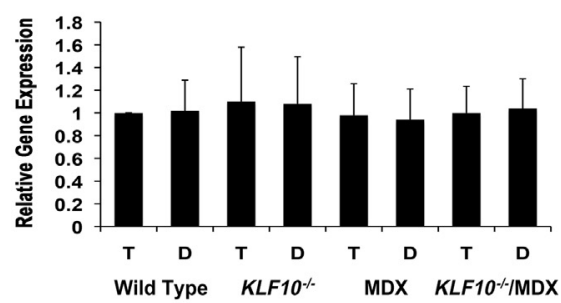

SMAD7

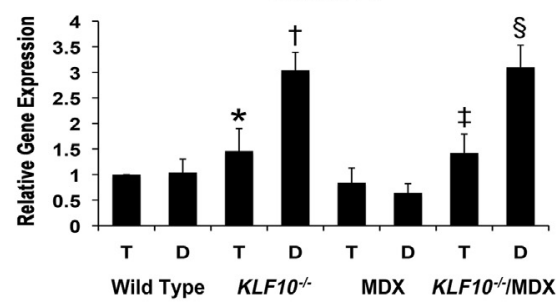

Figure 1 Gene expression analysis of KLF1Odeficient wild-type and mdx mice. RNAs were isolated from tibialis anterior ( $\mathrm{T}$ ) and diaphragm (D) muscles of 1-year-old wild-type (WT), KLF10 ${ }^{-/}$, $\mathrm{mdx}$, and $K L F 10^{-/-} / \mathrm{mdx}$ mice. RT-PCR was performed, as described in Materials and Methods, for the following genes: KLF10, collagen type I (Col1a1), fibronectin (FN), matrix metalloproteinase 2 (MMP2), tissue inhibitor of MMPs 1 (TIMP1), plasminogen activator inhibitor type 1 (PAI1), and SMAD7. GAPDH was used as a normalizing control. Data are expressed as means \pm SEM relative gene expression levels. $n=6$. ${ }^{*} P<0.05$ experimental tibialis anterior versus wild-type control; ${ }^{\dagger} P<0.05$ experimental diaphragm versus wild-type control; ${ }^{\ddagger} P<0.05 \mathrm{KLF10^{-/- }} / \mathrm{mdx}$ versus $\mathrm{mdx}$ tibialis anterior; ${ }^{\S} P<0.05 \mathrm{KLF} 1 \mathrm{O}^{-/-} / \mathrm{mdx}$ versus $\mathrm{mdx}$ diaphragm. increased relative to TA muscle. However, both $\mathrm{mdx}$ and $K L F 10^{-/-} / \mathrm{mdx}$ diaphragm and TA muscles had increased levels of fibronectin gene expression relative to wild-type and $\mathrm{KLFlO}^{-1-}$ mouse muscles. Moreover, fibronectin gene expression in $K L F 10^{-1-} / \mathrm{mdx}$ diaphragm muscle was significantly increased compared with $\mathrm{mdx}$ diaphragm muscle. In total, these results indicate that loss of KLF10 gene expression increased Collal and fibronectin gene expression, particularly in the diaphragm muscle of $\mathrm{mdx}$ mice.

Expression of genes associated with extracellular matrix remodeling was also analyzed. $M M P 2$ gene expression was significantly, but modestly, increased in both diaphragm and TA muscles from $K L F 10^{-1-}$ mice compared with wild-type controls. The mdx diaphragm displayed increased expression relative to wild-type diaphragm, and both diaphragm and TA muscles from $K L F 10^{-1-} / \mathrm{mdx}$ mice had increased $M M P 2$ gene expression relative to wild-type muscles. Also, loss of KLF10 gene expression in mdx TA muscle $\left(K L F 10^{-1-} / \mathrm{mdx}\right)$ increased MMP2 gene expression. TIMP1 gene expression did not significantly vary between diaphragm and TA muscles across each of the genotypes tested. Similarly, PAI-1 gene expression did not significantly change.

Previous research has shown that KLF10 can repress $S M A D 7$ gene expression, which normally down-regulates TGF- $\beta$-induced cell signaling. ${ }^{32}$ In $K L F 10^{-\prime-}$ and $K L F 10^{-1-} / \mathrm{mdx}$ mice, SMAD7 gene expression was increased in both diaphragm and TA muscles compared with wild-type and $\mathrm{mdx}$ mice, respectively. These results indicate that expression of profibrotic Collal and fibronectin genes occurs despite increased SMAD7 gene expression. 
Western blot analysis was performed on whole-cell extracts of diaphragm and TA muscles from 1-year-old wild-type, $K L F 10^{-\prime-}, \mathrm{mdx}$, and $K L F 10^{-/-} / \mathrm{mdx}$ mice (Figure 2). KLF10 protein was detected in mdx diaphragm extracts only. Fibronectin protein was detected in all cell extracts, with an increased abundance in extracts from $\mathrm{mdx}$ and $K L F 10^{-/-} / \mathrm{mdx}$ diaphragm muscle extracts. Furthermore, fibronectin protein content was increased in $K L F 10^{-1-} / \mathrm{mdx}$ versus $\mathrm{mdx}$ diaphragm muscle extract. EMyHC was detected in diaphragm muscle from both $\mathrm{mdx}$ and $\mathrm{KLF} \mathrm{O}^{-1-} / \mathrm{mdx}$ mice. It was not detected in any extracts of TA muscle. TGF- $\beta$ R 1 protein was detected in all cell extracts at similar levels.

Differences in protein content for SMAD2, SMAD3, SMAD4, and SMAD7 were observed. SMAD2 protein was detected in each cell extract, except those extracts from wildtype and mdx diaphragm. In contrast, SMAD3 protein was only detected in appreciable amounts in cell extracts from
$K L F 10^{-1-} / \mathrm{mdx}$ mice. Both diaphragm and TA muscles from $K L F 10^{-1-} / \mathrm{mdx}$ mice contained SMAD3 protein. SMAD4 protein was detected in all cell extracts, and diaphragm muscle from $K L F 10^{-1-}$, $\mathrm{mdx}$, and $K L F 10^{-1-} / \mathrm{mdx}$ mice contained more detectable SMAD4 protein (approximately 2.5 -fold) compared with wild-type diaphragm and all TA muscle. Last, and in agreement with RT-PCR data, SMAD7 protein was detected in diaphragm muscle from both $K L F 10^{-1-}$ and $K L F 10^{-1-} / \mathrm{mdx}$ mice. These results demonstrate differences between diaphragm and TA muscles with respect to genotype-specific detection of SMAD2 and SMAD7. The results also demonstrate non-muscle-specific differences in SMAD3 protein content, with detectable levels in both muscle types restricted to the $K L F 10^{-1-} / \mathrm{mdx}$ genotype only.

To further investigate the effect of loss of KLF10 on SMAD2/3 function in wild-type and dystrophic diaphragm and TA muscles, muscle sections were immunostained with a
A

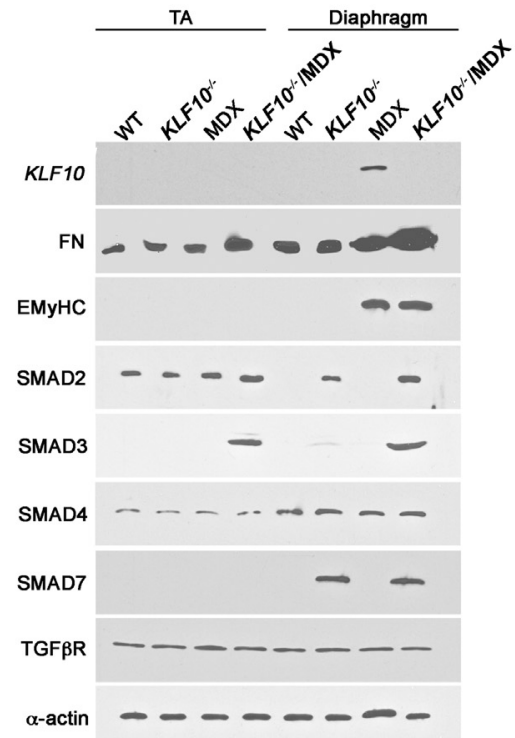

B
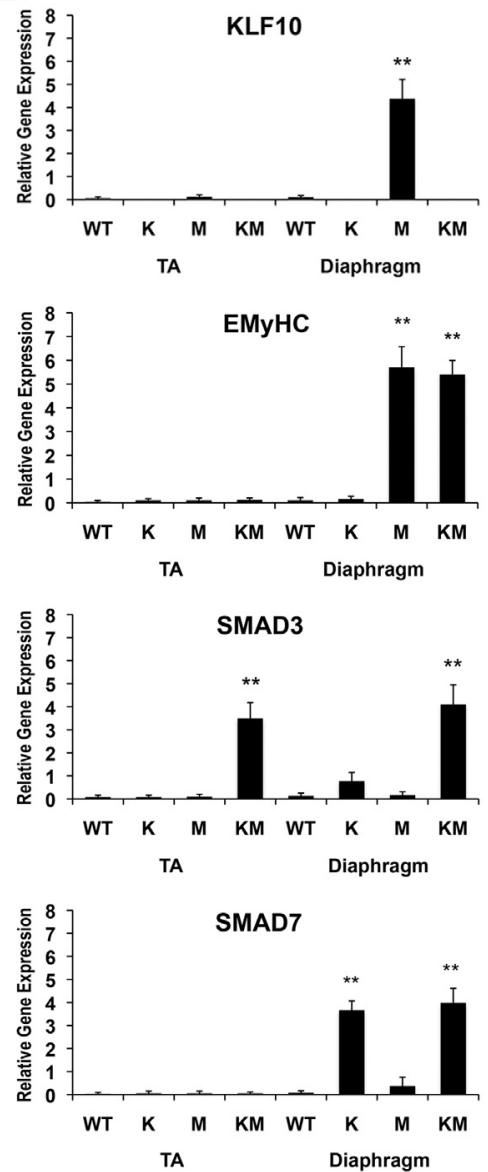

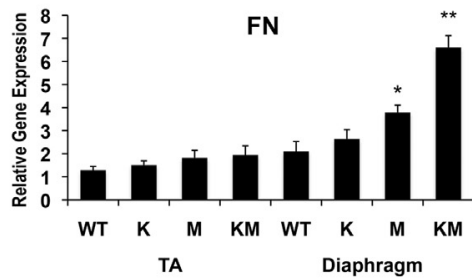

SMAD2

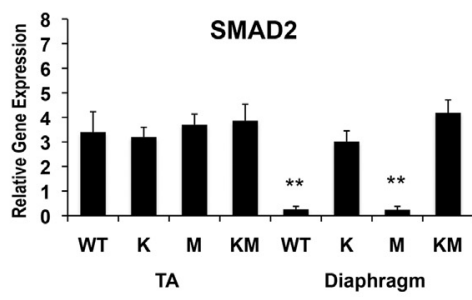

SMAD4

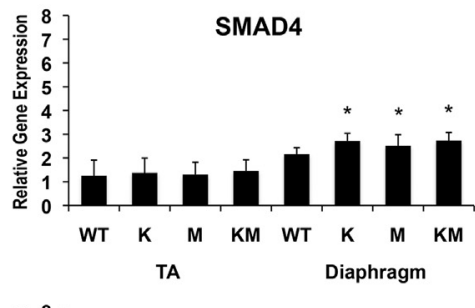

TGF $\beta R$

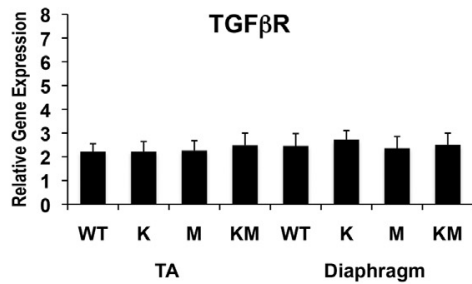

Figure 2 Detection and quantitation of proteins by Western blot analyses. A: For Western blots, protein extracts from 1-year-old tibialis anterior (TA) and

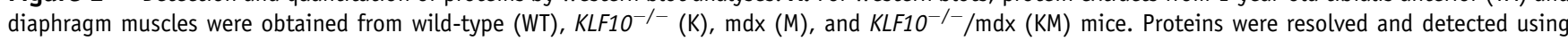
protein-specific antibodies (Materials and Methods). $\alpha$-Actin served as a loading control. The blot shown is representative of analyses of three mice of each genotype. B: Protein bands were quantitated using ImageJ software version 1.46 and normalized to the corresponding $\alpha$-actin protein bands to compare protein abundance with muscle fiber protein content. There were significant differences in the means of protein content between muscles of experimental genotypes and the respective wild-type controls. Data are expressed as means \pm SEM relative gene expression levels. $n=3(\mathbf{B})$. ${ }^{\star} P<0.05,{ }^{* *} P<0.01$ versus wild-type. EMyHC, embryonic myosin heavy chain; FN, fibronectin; TGF- $\beta$ R, transforming growth factor- $\beta$ receptor. 
A

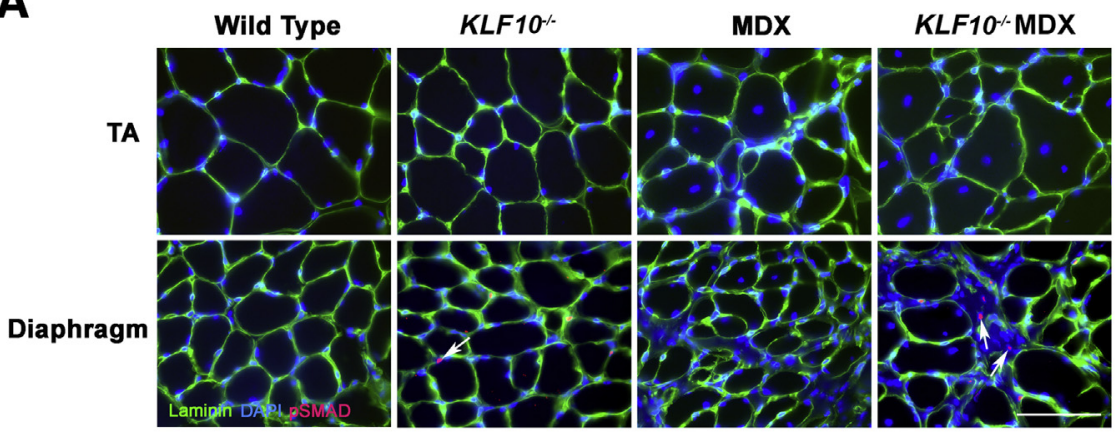

B

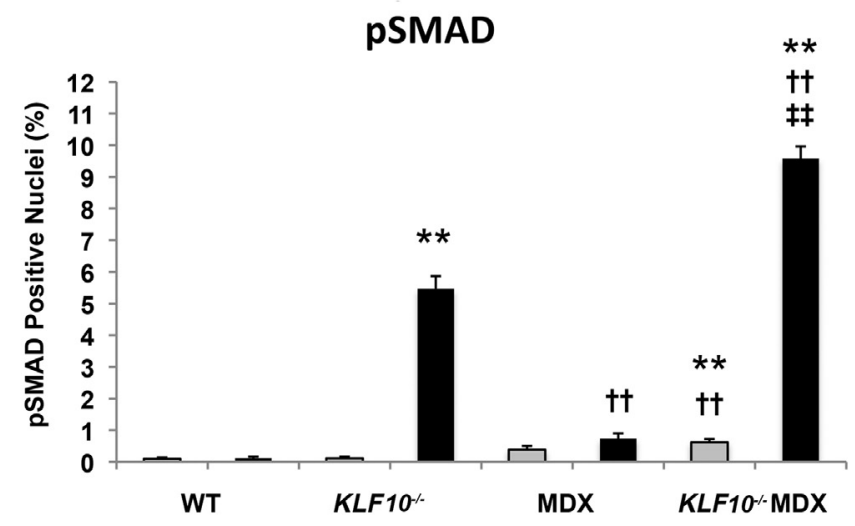

Figure 3 Detection and quantitation of phosphorylated (phospho)-SMAD2/3 (pSMAD2/3)positive nuclei. A: Cryosections of tibialis anterior (TA) and diaphragm muscles from 1-year-old wildtype, $K L F 10^{-/-}, \mathrm{mdx}$, and $K L F 10^{-/-} / \mathrm{mdx}$ mice were immunostained with a phospho-SMAD2/3specific antibody. Nuclei were stained with DAPI. A serial section was immunostained with a lamininspecific antibody. Images were added to each other using Photoshop CS6 software version 13.0.6 (Adobe Systems, San Jose, CA). Phospho-SMAD2/3 and laminin antibodies were detected using a Texas red- and fluorescein isothiocyanateconjugated secondary antibody, respectively. Arrows indicate phospho-SMAD2/3-positive nuclei. B: The number of phospho-SMAD2/3-positive nuclei relative to all nuclei per microscopic field was determined. Six fields were selected at random from each section, and six sections per muscle were analyzed. Muscle samples were collected from six mice of each genotype. Means of percentage $p$ SMAD-positive nuclei of each genotype were compared with wild-type (WT), KLF10 ${ }^{-/}$, and $\mathrm{mdx}$. ${ }^{* *} P<0.01$ versus WT; ${ }^{\dagger \dagger} P<0.01$ versus $K L F 10^{-/-}$; ${ }_{\ddagger \ddagger} P<0.01$ versus $\mathrm{mdx}$. Scale bar $=100 \mu \mathrm{m}(\mathbf{A})$.

phospho-SMAD2/3-specific antibody to detect active nuclear localized SMAD2/3 (Figure 3A). Phospho-SMAD2/3 was not detected in sections of wild-type diaphragm and TA muscles. Similarly, nuclear localized SMAD2/3 was not detected in sections of mdx diaphragm and TA muscles. As anticipated, centrally located nuclei in both mdx muscle sections were readily apparent, indicative of regenerated muscle fibers. ${ }^{44}$ Phospho-SMAD2/3 was not detected in sections of TA muscle from $K L F 10^{-1-}$ and $K L F 10^{-1-} / \mathrm{mdx}$ mice. However, phospho-SMAD2/3 was present in sections of diaphragm muscle from these mice. Phospho-SMAD2/3 immunostaining colocalized with DAPI staining of nuclei. The relative number of phospho-SMAD2/3-positive nuclei was determined for each muscle of each genotype (Figure 3B). Significantly greater numbers of phospho-SMAD2/ 3 -positive nuclei were observed in diaphragm muscle from $K L F 10^{-1-}$ versus wild-type and from $K L F 10^{-1-} / \mathrm{mdx}$ versus mdx mice.

\section{Assessment of Fibrosis and EMyHC Gene Expression}

Cryosections of wild-type, $K L F 10^{-/-}, \mathrm{mdx}, \quad$ and $K L F 10^{-1-} / \mathrm{mdx}$ diaphragm and TA muscles were stained for the fibrotic markers, collagen and fibronectin. Collagen was detected with Masson trichrome stain (Figure 4). Wild-type diaphragm and TA muscles showed no appreciable accumulation of collagen. Similarly, the TA muscle of $\mathrm{KLFlO}^{-/-}$muscle did not stain for collagen. Minor accumulations of collagen were noted in $\mathrm{KLF}^{-10^{--}}$diaphragm muscle sections. TA muscle sections from $\mathrm{mdx}$ mice also displayed minor collagen accumulation. More pronounced collagen deposition was observed in mdx diaphragm muscle and in $K L F 10^{-1-} / \mathrm{mdx}$ TA muscle. Most noticeably, significant collagen deposition was observed in diaphragm muscle sections from $K L F 10^{-1-} / \mathrm{mdx}$ mice.

Analysis of hydroxyproline content was performed to provide additional quantitative assessment of fibrosis, as defined by collagen content, in TA and diaphragm muscles of each genotype (Figure 5). Muscles were carefully trimmed of visible connective tissue outside the muscle epimysium, weighed, and hydrolyzed, as described in Materials and Methods. The amount of hydroxyproline relative to muscle wet weight in TA muscles from mice across all four genotypes was not significantly different. With regard to diaphragm muscle, there was no significant difference in hydroxproline content between wild-type and $K L F 10^{-1-}$ mice. Yet, both $\mathrm{mdx}$ and $K L F 10^{-1-} / \mathrm{mdx}$ mice had significantly more hydroxyproline compared with wildtype mice. More important, diaphragm muscle from $K L F 10^{-1-} / \mathrm{mdx}$ mice had approximately $48 \%$ more hydroxyproline than mdx diaphragm muscle.

Similar accumulation of fibronectin was observed in sections using an anti-fibronectin antibody (Figure 6). Fibronectin is a normal constituent of muscle fiber basal lamina and was detected in lamina surrounding each fiber. However, significant amounts of fibronectin were detected 


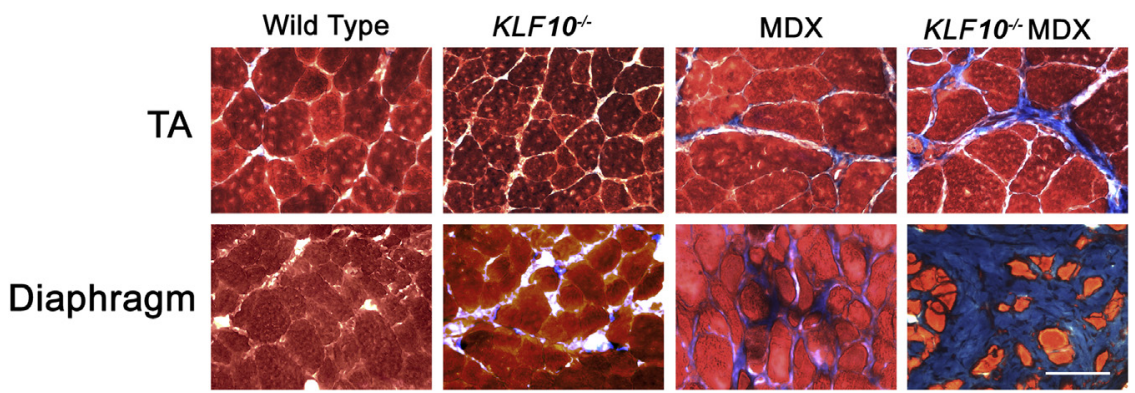

Figure 4 Histological analysis of fibrosis. Cryosections of tibialis anterior (TA) and diaphragm muscles from 1-year-old wild-type, $\mathrm{KLF1O}^{-1-}$, $\mathrm{mdx}$, and $\mathrm{KLF} \mathrm{O}^{-/-} / \mathrm{mdx}$ mice were stained with Masson trichrome stain to detect collagen (blue). Sections were counterstained with eosin (red) to visualize muscle fibers. The images are representative of analyses of six mice of each genotype. Scale bar $=50 \mu \mathrm{m}$. in interstitial spaces of diaphragm muscle from $\mathrm{mdx}$ and $K L F 10^{-/-} / \mathrm{mdx}$ mice, with the most noticeable accumulation in the latter. These results, coupled with quantitation of fibronectin protein content via Western blot analysis, indicate extensive fibrosis in $K L F 10^{-1-} / \mathrm{mdx}$ mice, with the most pronounced fibrosis detected in the diaphragm muscle.

EMyHC gene expression in TA and diaphragm muscle cross sections from 1-year-old mice was assessed by immunodetection using an EMyHC-specific monoclonal antibody (Figure 7). EMyHC was consistently absent from TA muscle, regardless of the genotype tested. EMyHC was also absent from diaphragm muscle of wild-type and $\mathrm{KLF}^{-1-}$ mice. However, EMyHC was detected in diaphragm muscle from both $\mathrm{mdx}$ and $K L F 10^{-1-} / \mathrm{mdx}$ mice. The percentage of muscle fibers expressing EMyHC was $1.8 \pm 0.6$ and $2.3 \pm 0.8$ in $\mathrm{mdx}$ and $\mathrm{KLF} 1 \mathrm{O}^{-1-} / \mathrm{mdx}$ diaphragm muscles, respectively. These values are not significantly different.

\section{Muscle Morphometry}

To determine whether the absence of the KLF10 gene affected muscle fiber size and the relative contribution of contractile muscle fibers to overall muscle size, TA and diaphragm muscle cross sections from each mouse genotype were immunostained with an anti-laminin antibody to detect muscle fiber basal lamina (Figure 7). Muscle fiber cross-sectional areas within the basal lamina were measured as described in Materials and Methods (Figure 8). The average crosssectional area of TA muscle fibers in $K L F 10^{-1-}$ mice did not vary significantly from the average cross-sectional area of wild-type TA muscle fibers. Similarly, the average crosssectional areas of $\mathrm{KLFlO}^{-1-}$ diaphragm muscle fibers were not significantly different from wild-type muscle fibers. However, the average areas of both $\mathrm{mdx}$ and $\mathrm{KLF} \mathrm{O}^{-1-} / \mathrm{mdx}$ muscle fibers were significantly reduced compared with wildtype and $K L F 10^{-1-}$ muscle fibers. Significant reductions in muscle fiber areas were evident in both TA and diaphragm muscles. The mdx and $K L F 10^{-/-} / \mathrm{mdx}$ muscle fibers in both muscles showed similar reductions in average cross-sectional areas of approximately 35\% relative to wild-type and $K L F 10^{-1-}$ muscle fibers, respectively.

Analysis of the relative proportion of contractile muscle fiber area to total muscle cross-sectional area revealed relative reductions in contractile tissue area in each of the experimental genotypes compared with wild-type control muscle (Figure 8). TA muscle from $K L F 10^{-1-} / \mathrm{mdx}$ demonstrated a modest, but significant, reduction in total muscle fiber area compared with wild-type TA muscle. With regard to diaphragm muscle, the

\section{Collagen Content}

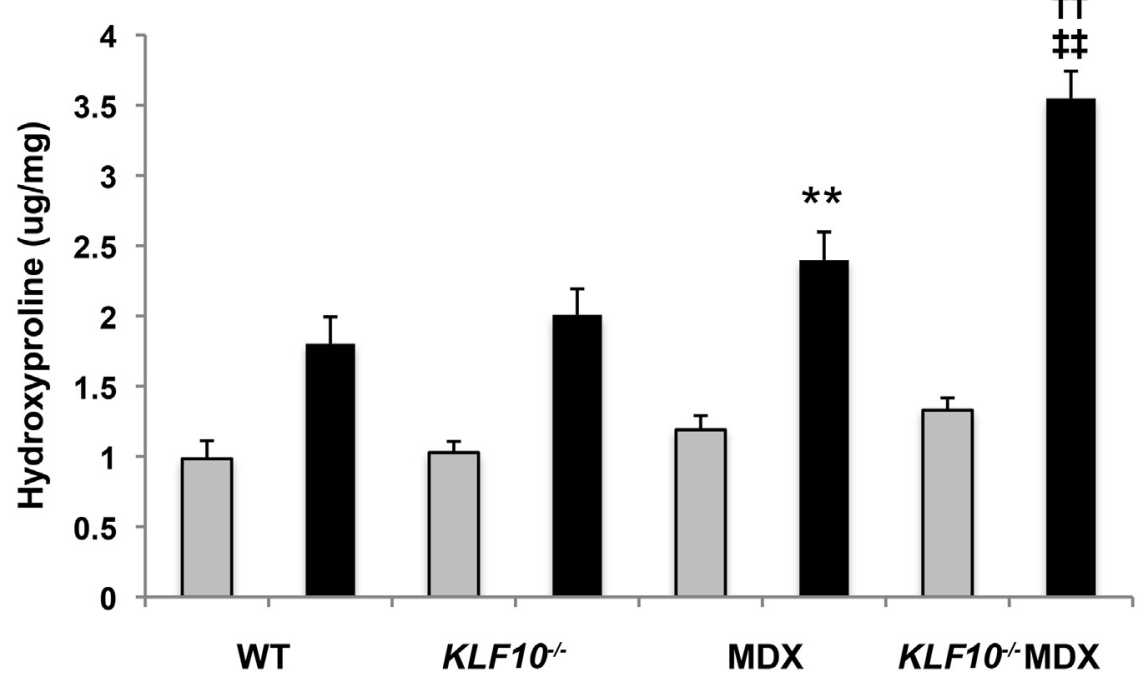

Figure 5 Analysis of collagen content. The amounts of hydroxyproline were measured in tibialis anterior (gray bars) and diaphragm (black bars) muscles from 1-year-old wild-type (WT), $\mathrm{KLF} \mathrm{O}^{-/-}$, $\mathrm{mdx}$, and $\mathrm{KLF10^{-/- }} / \mathrm{mdx}$ mice. Hydroxyproline content, as determined by comparison to a standard curve of known amounts of hydroxyproline, was normalized to muscle wet weight. Means of collagen content of each genotype were compared with wild-type, $K L F 10^{-/-}$, and $\mathrm{mdx}$ mice. Data are expressed as means \pm SEM. $n=6 .{ }^{* *} P<0.01$ versus $\mathrm{WT} ;{ }^{\dagger \dagger} P<0.01$ versus $K L F 10^{-/-} ;{ }^{\ddagger \ddagger} P<0.01$ versus $\mathrm{mdx}$. 

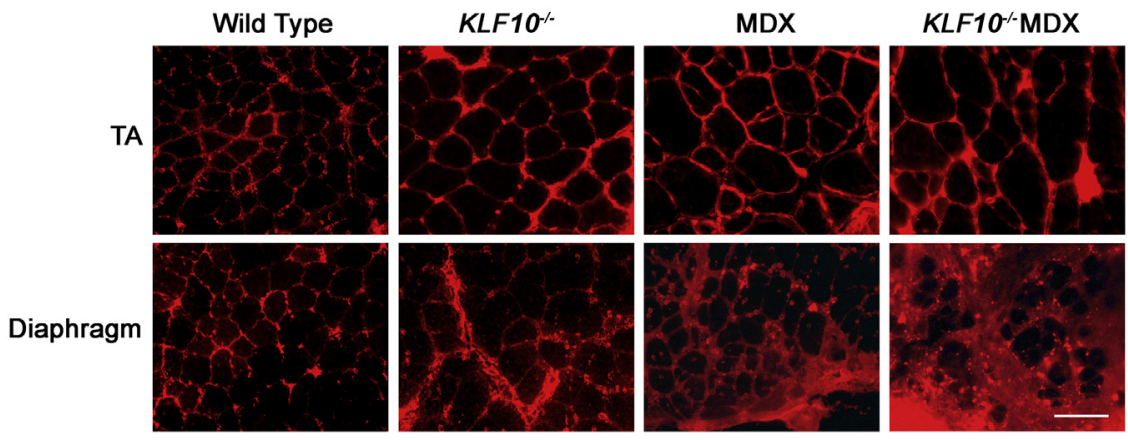

Figure 6 Immunolocalization of fibronectin protein. Cryosections of tibialis anterior (TA) and diaphragm muscles from 1-year-old wild-type, $K L F 10^{-I-}, \mathrm{mdx}$, and $K L F 10^{-/-} / \mathrm{mdx}$ mice were immunostained with an anti-fibronectin antibody and fluorochrome-conjugated secondary antibody. The images are representative of analyses of six mice of each genotype. Scale bar $=50 \mu \mathrm{m}$.

percentage muscle fiber area in $K L F 10^{-1-}$ muscle was significantly reduced compared with wild-type muscle $(84.9 \% \pm 0.52 \%$ versus $89.1 \% \pm 0.81 \%)$. The percentage of muscle fiber area in mdx diaphragm was also reduced compared with wild-type diaphragm muscle $(83.1 \% \pm 1.3 \%$ versus $89.1 \% \pm 0.81 \%$ ). The percentage muscle fiber area in $K L F 10^{-1-} / \mathrm{mdx}$ diaphragm muscle was also significantly reduced $(53.6 \% \pm 1.31 \%)$ compared with wild-type muscle. Moreover, the percentage area composed of muscle fibers in $K L F 10^{-/-} / \mathrm{mdx}$ diaphragm was significantly reduced compared with mdx diaphragm. Therefore, deletion of the KLF10 gene in the background of wild-type and $\mathrm{mdx}$ genotypes significantly reduced contractile muscle tissue area relative to whole muscle area.

\section{Functional Assessment}

To determine whether the loss of KLF10 caused effects on muscle function, grip strength was measured in mice of each genotype (Figure 9). KLF10 ${ }^{-1-}$ mice displayed the same grip strength as wild-type mice. The mdx mice, both female and male, had reduced grip strength compared with wildtype mice. More important, $K L F 10^{-1-} / \mathrm{mdx}$ displayed significantly reduced grip strength compared with $\mathrm{mdx}$ mice. Female and male strengths were reduced by $26.6 \%$ and $29.3 \%$, respectively, compared with mdx mice and $48.2 \%$ and $48.7 \%$, respectively, compared with wild-type mice. These results further establish a causative link of loss of KLF10 with increased fibrosis and loss of muscle function, particularly in dystrophic muscle.

\section{Discussion}

Many muscular dystrophies are partly characterized by increased deposition of extracellular matrix components, such as collagen and fibronectin, in response to chronic muscle damage. This fibrosis has important negative effects on normal muscle structure, function, and regenerative processes. ${ }^{5,6,45}$ Similar to the response to damage in other tissues, chronic skeletal muscle tissue damage results in

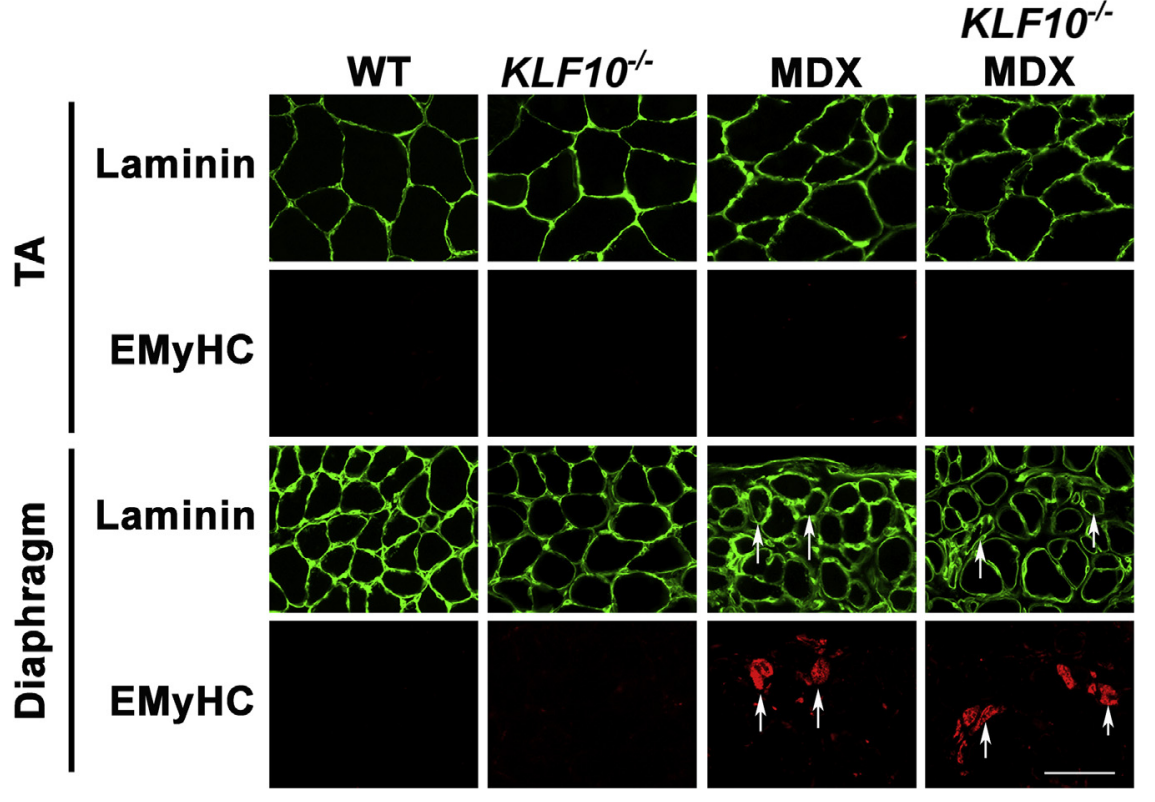

Figure 7 Immunodetection of embryonic myosin heavy chain (EMyHC) and laminin. Cryosections of tibialis anterior (TA) and diaphragm muscles from 1-year-old wild-type (WT), KLF10 ${ }^{-/-}$, $\mathrm{mdx}$, and $K L F 10^{-/-} / \mathrm{mdx}$ mice were immunostained with anti-EMyHC and anti-laminin antibodies, followed by fluorochrome-conjugated secondary antibodies. Arrows indicate muscle fibers containing EMyHC. The images are representative of analyses of six mice of each genotype. Scale bar $=50 \mu \mathrm{m}$. 
A

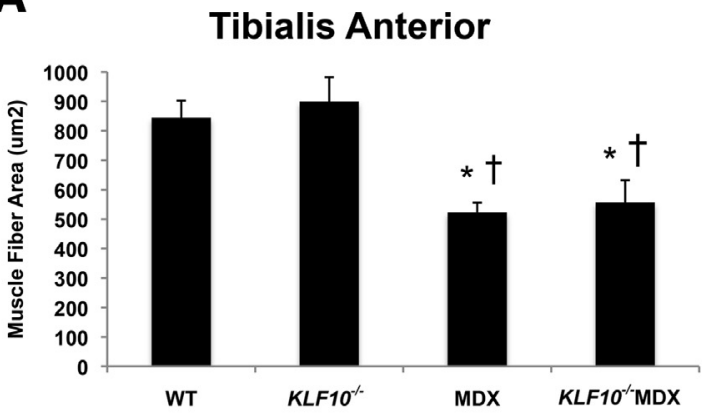

C

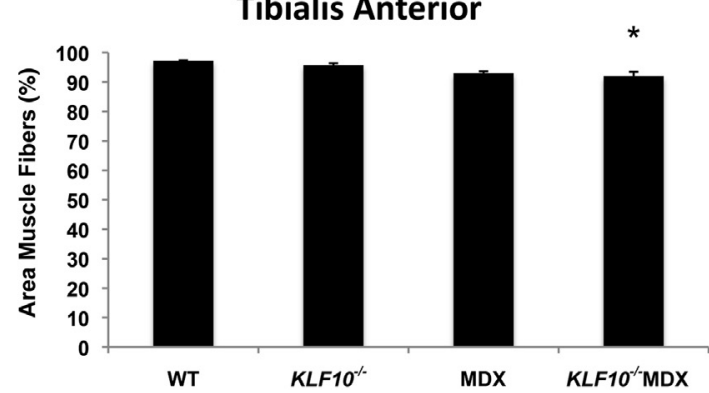

B

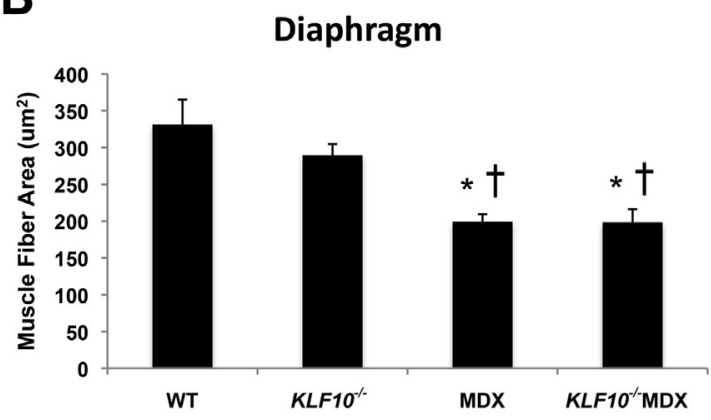

D

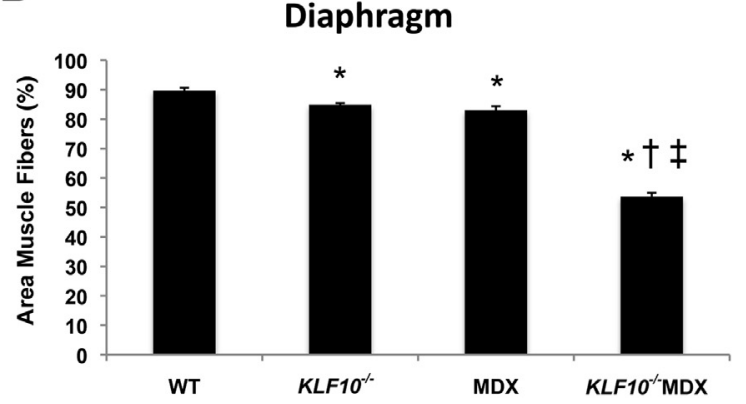

Figure 8 Quantitation of muscle fiber cross-sectional area and fibrosis. A and B: The average muscle fiber cross-sectional areas for tibialis anterior and

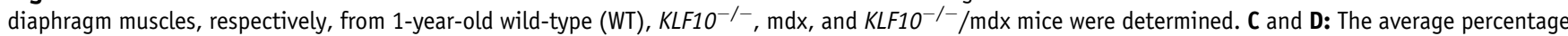
of muscle tissue composed of muscle fibers was also determined for each muscle from each genotype. Means of each genotype were compared with wild-type, $K L F 10^{-/-}$, and $\mathrm{mdx}$ mice. Data are expressed as means \pm SEM. $n=6(\mathbf{A}-\mathbf{D}) .{ }^{*} P<0.05$ versus WT; ${ }^{\dagger} P<0.05$ versus $K L F 10^{-/-} ;{ }^{\ddagger} P<0.05$ versus mdx.

elevated TGF- $\beta$ signaling activity, and it is this activity that appears to initiate and sustain the fibrotic response to such tissue damage. ${ }^{10,11}$

The KLF10 gene is transcriptionally activated as part of the early response to activation of the TGF- $\beta$ signaling pathway. ${ }^{21}$ Because KLF10 is a transcriptional effector of TGF- $\beta$ signaling, a KLF10 gene knockout mouse model was investigated for its role in regulating normal muscle tissue structure in wild-type mice and for its role in muscle tissue structure in the mdx mouse model of Duchenne muscular dystrophy. The KLF10 gene was expressed at basal levels in wild-type TA and diaphragm muscles, and its expression was increased in mdx muscles. The increase was modest in TA muscles and more pronounced in the diaphragm. The absence of KLF10 gene expression significantly increased Collal and fibronectin gene expression and protein deposition, particularly in the mdx diaphragm, exacerbating the fibrotic phenotype.

Expression of genes encoding the TGF- $\beta$ signaling effectors SMAD2, 3, 4, and 7 was assessed in the context of

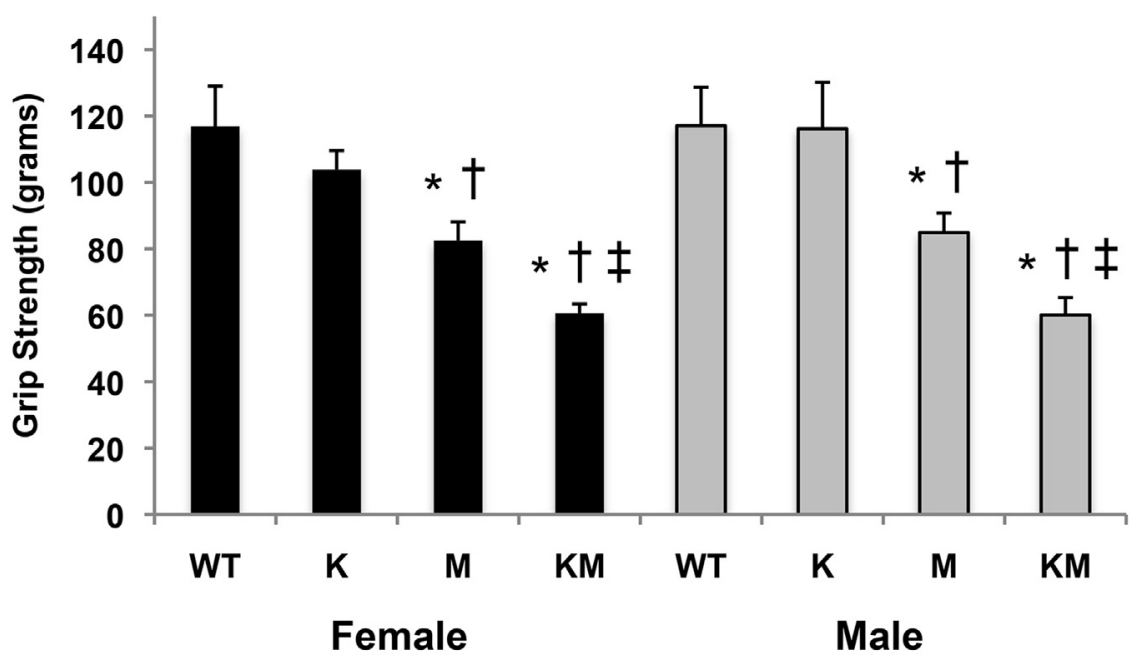

Figure 9 Assessment of muscle function by grip strength. Wild-type (WT), KLF10 ${ }^{-/-}(\mathrm{K})$, mdx (M), and $K L F 10^{-/-} / \mathrm{mdx}(\mathrm{KM})$ mice were measured for grip strength. Five female and five male mice of each genotype were assessed using five repetitions for each mouse. Means of grip strength of each ge-

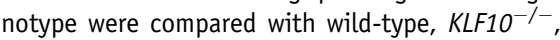
and $\mathrm{mdx}$ mice. Data are expressed as means $\pm \mathrm{SEM}$. $n=5$. ${ }^{\star} P<0.05$ versus $\mathrm{WT} ;{ }^{\dagger} P<0.05$ versus KLF10 ${ }^{-/-} ;{ }^{\ddagger} P<0.05$ versus $\mathrm{mdx}$. 
KLF10 gene expression in wild-type and mdx mice. SMAD2 protein was detected in TA muscle, regardless of the genotype tested. However, SMAD2 protein was absent in wildtype and mdx diaphragm and present in $K L F 10^{-1-}$ muscles, indicating that KLF10 may repress $S M A D 2$ gene expression in the diaphragm. SMAD3 protein was detected in $K L F 10^{-1-} / \mathrm{mdx}$ TA and diaphragm muscles, suggesting that KLF10 may also repress SMAD3 gene expression in these muscles. Furthermore, phosphorylated SMAD2/3 was detected in nuclei of $\mathrm{KLF}^{-1-}$ and $\mathrm{KLF}^{-10^{-/}} / \mathrm{mdx}$ diaphragm muscle. These results are important in light of the established role of SMAD2 and SMAD3 in the development of tissue fibrosis. ${ }^{6}$ SMAD4 protein was more abundant in diaphragm versus TA muscle protein extracts, but no differences corresponding to genotypes were readily observed. SMAD7 protein was detected in $K L F 10^{-1-}$ and $K L F 10^{-\prime}$ $-/ \mathrm{mdx}$ diaphragm muscle protein extracts and was not detected in the other extracts. This pattern of SMAD7 gene expression suggests that KLF10 represses SMAD7 gene expression, and this result is in agreement with previous findings. ${ }^{32}$ No discernible change in TGF- $\beta R 1$ protein content was observed in any of the protein extracts tested. Overall, these gene expression studies indicate that KLF1O gene expression is increased in regenerating (EMyHC-positive) muscles that show signs of fibrosis (eg, mdx diaphragm). However, the loss of KLF10 gene expression in these same muscles resulted in dysregulation of SMAD gene expression. SMAD2 and SMAD3, which are positive effectors of TGF- $\beta$ signaling, were increased in mdx muscles in the absence of KLF10. Therefore, as an immediate early gene of TGF- $\beta$ signaling, KLF10 may, at least transiently, repress $S M A D 2$ and $S M A D 3$ gene expression and thereby modulate the fibrotic response to muscle damage.

The dysregulation of SMAD gene expression in the absence of the KLF10 gene correlated with increased fibrosis. Marked collagen and fibronectin gene expression and protein deposition were detected in the $\mathrm{mdx}$ diaphragm and $\mathrm{KLFlO}^{-1-} / \mathrm{mdx}$ $\mathrm{TA}$ and diaphragm muscles. Furthermore, fibrosis was increased in $K L F 10^{-1-} / \mathrm{mdx}$ muscles compared with $\mathrm{mdx}$. The altered patterns of SMAD gene expression in the absence of $K L F 10$ are partially in agreement with previous findings in other tissues. Similar to previous results, KLF10 appears to repress $S M A D 7$ gene expression. ${ }^{32}$ However, it has been reported that KLF10 increased expression of PAI-1 and $S M A D 2$, but not $S M A D 3$ or $S M A D 4$, in osteoblasts. ${ }^{32}$ The results presented herein indicate that KLF10 regulation of $S M A D 2$ and $S M A D 3$, but not SMAD4, may reflect differential tissue-specific TGF- $\beta$-induced signaling pathways, mediated by KLF10. Nonetheless, the absence of KLF10 has been correlated with fibrosis in other striated muscle tissue. For example, KLF10-deficient mice display cardiac hypertrophy with increased fibrosis. ${ }^{40}$

A reduction in average muscle fiber cross-sectional area was observed in $\mathrm{mdx}$ versus wild-type and in $K L F 10^{-/-} / \mathrm{mdx}$ versus $K L F 10^{-1-}$ TA and diaphragm muscles. The loss of KLF10 alone did not cause a significant reduction in average muscle fiber size. This latter result is not in direct agreement with a recent study that reported the effect of loss of KLF10 on muscle fiber size in mouse extensor digitorum longus and soleus muscles. ${ }^{46}$ In this study, loss of KLF10 resulted in increased mean muscle fiber size in both muscles. These results indicated that loss of KLF1O led to muscle fiber hypertrophy, the mechanism of which is unclear. The study did not examine hypertrophy of specific muscle fiber types. It is important to recognize basic differences in experimental design between this later study and the one reported herein. Perhaps most important, the former study used 3-month-old mice, and the experiments reported herein used 1-year-old mice. This age was considered a time point at which skeletal muscle had sufficient time to develop fibrosis under normal levels of activity. It is not known at what age similar fibrotic changes can first be detected. The differences in results may reflect the role of KLF10 in muscle structure and homeostasis over time. It is possible that hypertrophy is an early response to loss of KLF10. This response may be transient, evident at 3 months of age, and decline between 3 months and 1 year.

Such changes in muscle fiber morphometry may accompany other changes in muscle histology and function over time because of loss of KLF10. The loss of muscle fiber size over time from 3 months to 1 year may be accompanied, or because of, a commensurate increase in fibrotic tissue. This is evident in the results reported herein. One-year-old $K L F 10^{-1-}$ TA and diaphragm muscles displayed increased fibrosis relative to age-matched wild-type controls. Oneyear-old $K L F 10^{-1-} / \mathrm{mdx}$ muscles also had increased fibrosis relative to mdx mouse muscles. These changes in muscle architecture correlate with reduced muscle function, as determined by measurements of grip strength. Also, the morphometric results were supported by assays of hydroxyproline content, reflecting collagen deposition, in these muscles. The $\mathrm{mdx}$ and $K L F 10^{-I-} / \mathrm{mdx}$ diaphragm muscles had greater hydroxyproline levels than their respective controls (wild-type and mdx muscles, respectively). No significant difference in hydroxyproline content was detected between wild-type and $K L F 10^{-1-}$ muscles, yet fibrosis in $K L F 10^{-1-}$ diaphragm muscle was suggested by a significant decline in the percentage of muscle fiber area within sections of the muscle. This is likely because of other ECM components, such as fibronectin, contributing to fibrosis and relative loss of contractile tissue area. Nevertheless, the effect of the loss of KLF10 was most pronounced in the mdx diaphragm, a muscle that exhibits fibrosis and significant muscle fiber degeneration and regeneration. Therefore, the results reported herein indicate that KLF10 moderates fibrosis in the context of chronic muscle degeneration and regeneration.

\section{Acknowledgment}

I thank Dr. Thomas C. Spelsberg (Mayo Clinic) for providing the $K L F 10^{-/-}$mice. 


\section{References}

1. Durbeej M, Campbell KP: Muscular dystrophies involving the dystrophin-glycoprotein complex: an overview of current mouse models. Curr Opin Genet Dev 2002, 12:349-361

2. Carnwath JW, Shotton DM: Muscular dystrophy in the mdx mouse: histopathology of the soleus and extensor digitorum longus muscles. J Neurol Sci 1987, 80:39-54

3. DiMario JX, Uzman A, Strohman RC: Fiber regeneration is not persistent in dystrophic (mdx) mouse skeletal muscle. Dev Biol 1991, 148:314-321

4. Stedman HH, Sweeney HL, Shrager JB, Maguire HC, Panettieri RA, Petrof B, Narusawa M, Leferovich JM, Sladky JT, Kelly AM: The mdx mouse diaphragm reproduces the degenerative changes in Duchenne muscular dystrophy. Nature 1991, 352:536-539

5. Gillies AR, Lieber RL: Structure and function of the skeletal muscle extracellular matrix. Muscle Nerve 2011, 44:318-331

6. Kharraz Y, Guerra J, Pessina P, Serrano AL, Muñoz-Cánoves P: Understanding the process of fibrosis in Duchenne muscular dystrophy. Biomed Res Int 2014, 2014:965631

7. Smith LR, Barton ER: Collagen content does not alter the passive mechanical properties of fibrotic skeletal muscle in mdx mice. Am J Physiol Cell Physiol 2014, 306:C889-C898

8. Chang NC, Chevalier FP, Rudnicki MA: Satellite cells in muscular dystrophy: lost in polarity. Trends Mol Med 2016, 22:479-496

9. DiMario J, Strohman RC: Satellite cells from dystrophic (mdx) mouse muscle are stimulated by fibroblast growth factor in vitro. Differentiation 1988, 39:42-49

10. Dadgar S, Wang Z, Johnston H, Kesari A, Nagaraju K, Chen Y, Hill DA, Partridge TA, Giri M, Freishtat RJ, Nazarian J, Xuan J, Wang Y, Hoffman E: Asynchronous remodeling is a driver of failed regeneration in Duchenne muscular dystrophy. J Cell Biol 2014, 207:139-158

11. Quattrocelli M, Spencer MJ, McNally EM: Outside in: the matrix as a modifier of muscular dystrophy. Biochim Biophys Acta 2017, 1864: $572-579$

12. Zhou L, Porter JD, Chengetal G: Temporal and spatial mRNA expression patterns of TGF- $\beta 1,2,3$ and TGF $\beta R$ I, II, III in skeletal muscles of mdx mice. Neuromuscul Disord 2006, 16:32-38

13. Wynn TA: Cellular and molecular mechanisms of fibrosis. J Path 2008 , 214:199-210

14. Zanotti S, Saredi S, Ruggieri A, Fabbri M, Blasevich F, Romaggi S, Morandi L, Mora M: Altered extracellular matrix transcript expression and protein modulation in primary Duchenne muscular dystrophy myotubes. Matrix Biol 2007, 26:615-624

15. Massagué J, Cheifetz S, Endo T, Nadal-Ginard B: Type beta transforming growth factor is an inhibitor of myogenic differentiation. Proc Natl Acad Sci U S A 1986, 83:8206-8210

16. Brennan TJ, Edmondson DG, Olson E: Transforming growth factor beta represses the actions of myogenin through a mechanism independent of DNA binding. Proc Natl Acad Sci U S A 1991, 88: 3822-3826

17. Hartel JV, Granchelli JA, Hudecki MS, Pollina CM, Gosselin LE: Impact of prednisone on TGF-beta1 and collagen in diaphragm muscle of mdx mice. Muscle Nerve 2001, 24:428-432

18. Andreeta F, Bernasconi P, Baggi F, Ferro P, Oliva L, Arnoldi E, Cornelio F, Mantagazza R, Confalonieri P: Immunomodulation of TGF-beta 1 in mdx mouse inhibits connective tissue proliferation in diaphragm but increases inflammatory response: implications for antifibrotic therapy. J Neuroimmunol 2006, 175:77-86

19. Accornero F, Kanisicak O, Tjondrokoesoemo A, Attia AC, McNally EM, Molkentin JD: Myofiber-specific inhibition of TGF $\beta$ signaling protects skeletal muscle from injury and dystrophic disease in mice. Hum Mol Genet 2014, 23:6903-6915

20. Narola J, Pandey SN, Glick A, Chen YW: Conditional expression of TGF- $\beta 1$ in skeletal muscles causes endomysial fibrosis and myofibers atrophy. PLoS One 2013, 14:e79356
21. Subramaniam M, Harris SA, Oursler MJ, Rasmussen K, Riggs BL, Spelsberg TC: Identification of a novel TGF-beta-regulated gene encoding a putative zinc finger protein in human osteoblasts. Nucleic Acids Res 1995, 23:4907-4912

22. Tau KR, Hefferan TE, Waters KM, Robinson JA, Subramaniam M, Riggs BL, Spelsberg TC: Estrogen regulation of a transforming growth factor-beta inducible early gene that inhibits deoxyribonucleic acid synthesis in human osteoblasts. Endocrinology 1998, 139:1346-1353

23. Mitsumoto M, Mitsumoto A, Demple B: Nitric oxide-mediated upregulation of the TGF-beta-inducible early response gene-1 (TIEG1) in human fibroblasts by mRNA stabilization independent of TGF-beta. Free Radic Biol Med 2003, 34:1607-1613

24. Wahab NA, Weston BS, Mason RM: Connective tissue growth factor CCN2 interacts with and activates the tyrosine kinase receptor TrkA. J Am Soc Nephrol 2005, 16:340-351

25. Venuprasad K, Huang H, Harada Y, Elly C, Subramaniam M, Spelsberg T, Su J, Liu YC: The E3 ubiquitin ligase Itch regulates expression of transcription factor Foxp3 and airway inflammation by enhancing the function of transcription factor TIEG1. Nat Immunol 2008, 9:245-253

26. Lacmann A, Hess D, Gohla G, Roussa E, Krieglstein K: Activitydependent release of transforming growth factor-beta in a neuronal network in vitro. Neuroscience 2007, 150:647-657

27. Dijkmans TF, van Hooijdonk LW, Schouten TG, Kamphorst JT, Fitzsimons CP, Vreugdenhil E: Identification of new nerve growth factor-responsive immediate-early gene. Brain Res 2009, 1249:19-33

28. Cen M, Hu P, Cai Z, Fang T, Zhang J, Lu M: TIEG1 deficiency confers enhanced myocardial protection in the infracted heart by mediating the Pten/Akt signaling pathway. Int J Mol Med 2017, 39: $569-578$

29. Miyake M, Hayashi S, Iwasaki S, Uchida T, Watanabe K, Ohwada S, Aso H, Yamaguchi T: TIEG1 negatively controls the myoblast pool indispensible for fusion during myogenic differentiation of $\mathrm{C} 2 \mathrm{C} 12$ cells. J Cell Physiol 2011, 226:1128-1136

30. Parakati R, DiMario JX: Repression of myoblast proliferation and fibroblast growth factor receptor 1 promoter activity by KLF10 protein. J Biol Chem 2013, 288:13876-13884

31. Johnsen SA, Subramaniam M, Katagiri T, Janknecht R, Spelsberg TC: Transcriptional regulation of Smad2 is required for enhancement of TGFbeta/Smad signaling by TGFbeta inducible early gene. J Cell Biochem 2002, 87:233-241

32. Johnsen SA, Subramaniam M, Janknecht R, Spelsberg TC: TGFbeta inducible early gene enhances TGFbeta/Smad-dependent transcriptional responses. Oncogene 2002, 21:5783-5790

33. Goldstein JA, Bogdanovich S, Beiriger A, Wren LM, Rossi AE, Gao QQ, Gardner BB, Earley J, Molkentin JD, McNally EM: Excess SMAD signaling contributes to heart and muscle dysfunction in muscular dystrophy. Hum Mol Genet 2014, 23:6722-6731

34. Cohen TV, Kollias HD, Liu N, Ward CW, Wagner KR: Genetic disruption of Smad7 impairs skeletal muscle growth and regeneration J Physiol 2015, 593:2479-2497

35. Bensamoun SF, Hawse JR, Subramaniam M, Ilharreborde B, Bassillais A, Benhamou CL, Fraser DG, Oursler MJ, Amadio PC, An KN, Spelsberg TC: TGFbeta inducible early gene-1 knockout mice display defects in bone strength and microvasculature. Bone 2006, 39: 1244-1251

36. Hawse JR, Iwaniec UT, Bensamoun SF, Monroe DG, Peters KD, Ilharreborde B, Rajamannan NM, Oursler MJ, Turner RT, Spelsberg TC, Subramaniam M: TIEG-null mice display an osteopenic gender-specific phenotype. Bone 2008, 42:1025-1031

37. Kammoun M, Pouletaut P, Canon F, Subramaniam M, Hawse JR, Vayssade M, Bensamoun SF: Impact of TIEG1 deletion on the passive mechanical properties of fast and slow twitch skeletal muscles in female mice. PLoS One 2016, 11:e0164566

38. Bensamoun SF, Tsubone T, Subramaniam M, Hawse JR, Boumediene E, Spelsberg TC, An KN, Amadio PC: Age-dependent changes in the mechanical properties of tail tendons in TGF-beta 
inducible early gene-1 knockout mice. J Appl Physiol 2006, 101: $1419-1424$

39. Gumez L, Bensamoun SF, Doucet J, Haddad O, Hawse JR, Subramaniam M, Spelsberg TC, Pichon C: Molecular structure of tail tendon fibers in TIEG1 knockout mice using synchrotron diffraction technology. J Appl Physiol 2010, 108:1706-1710

40. Rajamannan NM, Subramaniam M, Abraham TP, Vasile VC, Ackerman MJ, Monroe DG, Chew TL, Spelsberg TC: TGFbeta inducible early gene-1 (TIEG1) and cardiac hypertrophy: discovery and characterization of a novel signaling pathway. J Cell Physiol 2017, 100:315-325

41. Subramaniam M, Gorny G, Johnsen SA, Monroe DG, Evans GL, Fraser DG, Rickard DJ, Rasmussen K, van Deursen JMA, Turner RT, Oursler MJ, Spelsberg TC: TIEG1 null mouse-derived osteoblasts are defective in mineralization and in support of osteoclast differentiation in vitro. Mol Cell Biol 2005, 25:1191-1199
42. Reddy GK, Enwemeka CS: A simplified method for the analysis of hydroxyproline in biological tissues. Clin Biochem 1996, 29:225-229

43. Carlson CG: Determination of hydroxyproline content as a measure of fibrosis in nondystrophic and dystrophic skeletal muscle. [Internet]. Treat NMD Neuromuscular Network, 2009. Available at www.treat-nmd.eu/ downloads/file/sops/dmd/MDX/DMD_M.1.2.006.pdf (last revised January 30, 2014)

44. Coulton GR, Morgan JE, Partridge TA, Sloper JC: The mdx mouse skeletal muscle myopathy, I: a histological, morphometric and biochemical investigation. Neuropathol Appl Neurobiol 1988, 14:53-70

45. Lieber RL, Ward SR: Cellular mechanisms of tissue fibrosis, 4: structural and functional consequences of skeletal muscle fibrosis. Am J Physiol Cell Physiol 2013, 305:C241-C252

46. Kammoun M, Meme S, Meme W, Subramaniam M, Hawse JR, Canon F, Bensamoun SF: Impact of TIEG1 on the structural properties of fast- and slow-twitch skeletal muscle. Muscle Nerve 2017, 55:410-416 